\title{
DEPRESSIVE DISORDERS IN COPD PATIENTS - ECONOMIC ASPECT
}

\author{
EDYTA RYSIAK ${ }^{1 *}$, IZABELA PROKOP'1, ILONA ZARĘBA¹, MILENA OSINSSKA² \\ and ROBERT MRÓZ $Z^{3,4}$
}

\author{
${ }^{1}$ Department of Medicinal Chemistry, Faculty of Pharmacy with the Division of Laboratory Medicine, \\ Medical University of Białystok, Mickiewicza 2D, 15-222 Białystok, Poland \\ ${ }^{2}$ Student's Scientific Group at Department of Medicinal Chemistry, \\ Medical University of Białystok, Poland \\ ${ }^{3}$ II Department of Lung Diseases and Tuberculosis, Medical University of Białystok, Poland \\ ${ }^{4}$ Respiratory Medicine Center, Białystok, Poland
}

\begin{abstract}
Chronic obstructive pulmonary disease is one of the most important health problems and one of the most common chronic diseases. The occurrence of COPD is associated with a particular dimension of physical suffering, the source of which is the difficulty in breathing. A significant percentage of patients experience the mental consequences of illness such as depression and anxiety disorders. The aim of the study was to analyze the prevalence of depressive symptoms in patients with medium-severe and severe forms of COPD and to assess the cost of coexistence of depression in this group of patients. The retrospective study, based on medical records, included two groups of patients: Group 1- 63 persons and Group 2-60 persons. The study evaluated the following parameters: degree of severity of COPD according to Global Initiative for Chronic Obstructive Lung Disease (GOLD), degree of severity of dyspnea using the mMRC scale of dyspnea developed by the Medical Research Council and occurrence of depressive symptoms and their severity using the Beck Depression Scale questionnaire. Patients were treated at the CENTER for Respiratory Medicine between January 2016 and December 2016. Results of our study showed that in both treatment groups analysis of the answers received from the Beck's Depression Scale questionnaire revealed that all these patients have depressive symptoms of varying severity.
\end{abstract}

Keywords: depression, COPD, pharmacoeconomics

COPD is characterized by incomplete reversible airflow limitation. This limitation is usually progressive and is associated with an abnormal pulmonary inflammatory response to harmful dust or gases (1). COPD is accompanied by extrapulmonary changes and co-morbid conditions that may contribute to the severity of the condition of the individual patients. COPD should be seen as lung disease, but coexisting diseases must be taken into account in a comprehensive diagnosis, in the assessment of severity of the disease, and in the determination of appropriate treatment.

Chronic obstructive pulmonary disease is one of the most important health problems and one of the most common chronic diseases. The Global Burden of Disease Study assessed COPD as the sixth leading cause of death in the world in the 1990 s, and it is estimated that by 2020 it will move to a third place (2). It is estimated that moderate or severe COPD has approx. 65 million people in the world. Studies show that COPD correlates with age (especially over 40 years of age) and the incidence of smoking, both now and in the past (3). The average incidence of disease in patients over 40 is about 9\%. COPD can occur in about $8-10 \%$ of Europe's population, who have completed 30 years of age (2). Studies report that COPD is currently one of the most common causes of disability and mortality. It is estimated that by 2020 it will become the fifth most important factor in the quality of life (4).

The occurrence of COPD is associated with a particular dimension of physical suffering, the source of which is the difficulty in breathing. A significant percentage of patients experience the mental consequences of illness such as depression and anxiety disorders (12-16). This is closely related to

* Corresponding author: e-mail: edyta.rysiak@umb.edu.pl 
younger age, female gender, smoking, lower FEV1 (forced expiratory volume in 1 second) value, cough, history of cardiovascular disease, and consequent poor prognosis $(13,16)$. From a psychological point of view, patients are difficult to cope with dyspnea attacks that generate anxiety and stress (6). Mood deterioration in this group of patients is closely associated with inflammatory cytokine activation, hypoxia associated with respiratory failure and cardiovascular disease, which contribute to psychomotor slowdown and cognitive decline, and thus mood deprivation. The side effects of systemic steroids used in COPD are also aggravated by mental deterioration (10).

Studies report that there is a close relationship between the occurrence of depressive symptoms in patients with COPD (7-9). It is believed that depression occurs in about $40-50 \%$ of patients with this disease unit (4-6, 9). Patients with COPD during long-term illness become particularly susceptible to severe depressive symptoms. It is recommended that in the medium-severe and severe forms of COPD lead psychotherapy as part of complex therapy (11, 12). Treatment of depression in patients with COPD should be conducted in accordance with the guidelines, as there is no data to suggest that therapeutic treatment should be different in coexisting with COPD (17).

The most important determinant of quality of life is health condition. Quality of life analysis in patients with COPD is essential because this disease affects all dimensions of the patient's functioning, such as physical, mental or social condition (23).
Lowering quality of life in COPD patients is primarily associated with onerous symptoms of dyspnea, cough, overproduction of lung secretions, and decreased respiratory function. Patients also suffer from chest pain as well as the co-occurrence of other diseases such as pneumonia, cardiovascular disease, which significantly affects the quality of life.

The aim of the study was to analyze the prevalence of depressive symptoms in patients with medium-severe and severe forms of COPD and to assess the cost of coexistence of depression in this group of patients.

\section{MATERIALS AND METHODS}

The study evaluated the following parameters:

1. The degree of severity of COPD- parameter was assessed according to Global Initiative for Chronic Obstructive Lung Disease (GOLD) (18).

2. Degree of severity of dyspnea- parameter was assessed using the mMRC scale of dyspnea developed by the Medical Research Council. This is a five-point scale describing the occurrence of dyspnea associated with daily activities (19).

3. The occurrence of depressive symptoms and their severity - the parameter was assessed using the Beck Depression Scale questionnaire (20). Evaluation of the results obtained from the scale as follows: 0-11 points - no depression or depressed mood, $12-18$ points - mild depression, 19-26 points- moderate depression, $27-49$ pointssevere depression, 50-63 points - very severe depression.

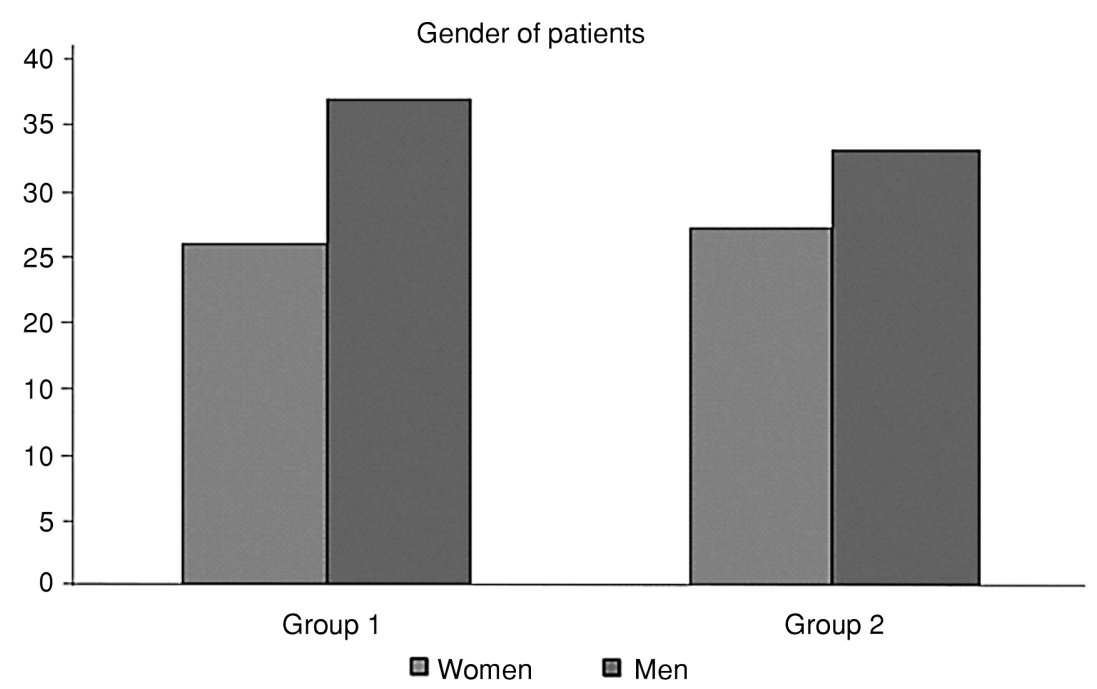

Figure 1. The gender distribution in the studied groups 
Table 1. Drugs used in the treatment of various stages of COPD in a stable period of illness- comparison of treatment costs (based on medication prices in force in 2016).

\begin{tabular}{|c|c|c|c|c|c|}
\hline $\begin{array}{l}\text { Name and } \\
\text { dose of } \\
\text { medicament }\end{array}$ & $\begin{array}{l}\text { Number } \\
\text { of } \\
\text { patients }\end{array}$ & $\begin{array}{c}\text { Cost of } 1 \\
\text { drug package } \\
\text { [euro] }\end{array}$ & $\begin{array}{l}\text { Cost of monthly } \\
\text { therapy for } 1 \text { patient } \\
\text { (including } \\
\text { reimbursement) } \\
\text { [euro] }\end{array}$ & $\begin{array}{l}\text { Cost of annual } \\
\text { therapy for } 1 \text { patient } \\
\text { (including } \\
\text { reimbursement) } \\
\text { [euro] }\end{array}$ & $\begin{array}{l}\text { General cost of } \\
\text { annual therapy of } \\
\text { patients in } \\
\text { the group } \\
\text { [euro] }\end{array}$ \\
\hline \multicolumn{6}{|c|}{ Group 1} \\
\hline Tiotropium bromide & \multirow{10}{*}{63} & 35.13 & 11.48 & 137.76 & 26558.28 \\
\hline $\begin{array}{l}\text { Budesonide/formoterol } \\
\text { fumarate } 80 \mu \mathrm{g} / 4.5 \mu \mathrm{g}\end{array}$ & & 18.15 & 4.74 & 56.88 & 13721.40 \\
\hline $\begin{array}{l}\text { Budesonide/formoterol } \\
\text { fumarate } 160 \mu \mathrm{g} / 4.5 \mu \mathrm{g}\end{array}$ & & 20.94 & 7.51 & 90.12 & 15830.64 \\
\hline $\begin{array}{l}\text { Budesonide/formoterol } \\
\text { fumarate } 320 \mu \mathrm{g} / 9 \mu \mathrm{g}\end{array}$ & & 40.65 & 10.47 & 125.64 & 30731.40 \\
\hline Fluticasone propionate 50 & & 23.38 & 4.25 & 51 & 17675.28 \\
\hline Fluticasone propionate 125 & & 28.71 & 5.82 & 69.84 & 21704.76 \\
\hline Fluticasone propionate 250 & & 42.56 & 12.38 & 148.56 & 32175.36 \\
\hline $\begin{array}{l}\text { Fluticasone propionate disk } \\
\text { inhaler } 100\end{array}$ & & 24.30 & 6.16 & 73.92 & 18370.80 \\
\hline $\begin{array}{l}\text { Fluticasone propionate disk } \\
\text { inhaler } 250\end{array}$ & & 30.52 & 7.63 & 91.56 & 23073.12 \\
\hline $\begin{array}{l}\text { Fluticasone propionate disk } \\
\text { inhaler } 500\end{array}$ & & 40.13 & 9.94 & 119.28 & 30338.28 \\
\hline \multicolumn{3}{|c|}{ Averaged cost of annual therapy } & & 96.46 & 23534.28 \\
\hline \multicolumn{6}{|c|}{ Group 2} \\
\hline $\begin{array}{l}\text { Tiotropium bromide }+ \\
\text { Formoterol fumarate } \\
\text { (Oxodil) }\end{array}$ & \multirow{6}{*}{60} & 49.69 & 12.24 & 146.94 & 35776.80 \\
\hline $\begin{array}{l}\text { Tiotropium bromide }+ \\
\text { Formoterol fumarate } \\
\text { (Foradil) }\end{array}$ & & 52.12 & 14.67 & 176.05 & 37526.40 \\
\hline $\begin{array}{l}\text { Tiotropium bromide }+ \\
\text { Budesonide/formoterol } \\
\text { fumarate } 160 \mu \mathrm{g} / 4.5 \mu \mathrm{g}\end{array}$ & & 56.07 & 18.99 & 227,88 & 40370.40 \\
\hline $\begin{array}{l}\text { Tiotropium bromide }+ \\
\text { Fluticasone propionate } 125\end{array}$ & & 63.84 & 17.31 & 207.68 & 45964.80 \\
\hline $\begin{array}{l}\text { Tiotropium bromide }+ \\
\text { Fluticasone propionate } \\
\text { Disk inhaler } 250\end{array}$ & & 65.65 & 19.12 & 229.40 & 47268.00 \\
\hline $\begin{array}{l}\text { Tiotropium bromide }+ \\
\text { Budesonide/formoterol } \\
\text { fumarate }(160 \mu \mathrm{g} / 4.5 \mu \mathrm{g})+ \\
\text { Fluticasone propionate } \\
\text { Disk inhaler } 250\end{array}$ & & 90.87 & 26.63 & 319.51 & 65426.40 \\
\hline \multicolumn{4}{|c|}{ Averaged cost of annual therapy } & 217.91 & 45388.80 \\
\hline
\end{tabular}

\section{Description of the study groups}

The retrospective study, based on medical records, included two groups of patients: Group 1-63 persons and Group 2-60 persons.

Group 1 included 63 patients with mild dyspnea $(\mathrm{mMRC}=1)$ or mild symptoms CAT (COPD
Assessment Test $)<10$ and severe and very severe bronchial obstruction (FEV1 $<50 \%$ ) with 2 exacerbations in the last 12 months. There were 26 women (41.3\%) and 37 men (58.7\%) among the patients. The mean age in the study group was 56.42 years $(\mathrm{SD}=13.17)$, the mean duration of illness 9.43 (SD 
= 3.23). 38 patients were working-age people, 11 people were working despite the illness, 27 people were on disability pension. Almost all respondents smoked large quantities of cigarettes ( $>20$ /day) for many years $(22.16$ years, $\mathrm{SD}=7.82)$. The highest number of patients was defined as the degree of dyspnea in the 1st degree on the mMRC 58 scale $(92.06 \%)$ and 5 patients below 1 degree, which accounted for $7.94 \%$ of the patients in the group.

Group 2 included 60 patients with severe dyspnea $(\mathrm{mMRC}=2)$ or severe symptoms $(\mathrm{CAT}=10)$ and severe and severe bronchial obstruction (FEV1 $<50 \%$ ) with 2 exacerbations in the last 12 months. There were 27 women (45\% of the group) and 33 men $(55 \%)$. The mean age in the study group was 63.11 years $(\mathrm{SD}=16.09)$, mean duration 17.72 (SD =8.56). 26 patients were working-age people, working 5 people, on disability pension were 21 people. Almost all respondents smoked large quantities of cigarettes ( $>$ 20/day) for many years (29.36 years, $\mathrm{SD}=10.23)$.

The majority of patients reported dyspnea in the range of 2-3 degrees mMRC-43 (71.67\%) and 17 (28.33\%) patients indicated 4-stage dyspnea.
Patients were treated at the CENTER for Respiratory Medicine between January 2016 and December 2016.

\section{RESULTS}

The study involved a total of 123 patients were randomized to two study groups differing in the degree of dyspnea or symptoms of the disease. Group 1, with a population of 63 patients, is characterized by mild dyspnea $(\mathrm{mMRC}=1)$ or mild disease $(\mathrm{CAT}<10)$. Group 2, with a population of 60 , is a patient with severe dyspnea $(\mathrm{mMRC}=2)$ or severe and severe disease $(\mathrm{CAT}=10)$. Gender distribution in each group is shown in Figure 1.

Patients at the time of the study were taking prescription drugs according to their recommendations for the disease stage. Summary of the costs of pharmacotherapy is shown in Table 1.

In each study group, the severity of depressive disorders was assessed. For this purpose, Beck's depression questionnaire was used. Patients responded to questions about their own psychophysical condition regarding the last week preceding the

Exacerbation of depressive disorders in the studied groups

घGroup $1 \quad \square$ Group 2

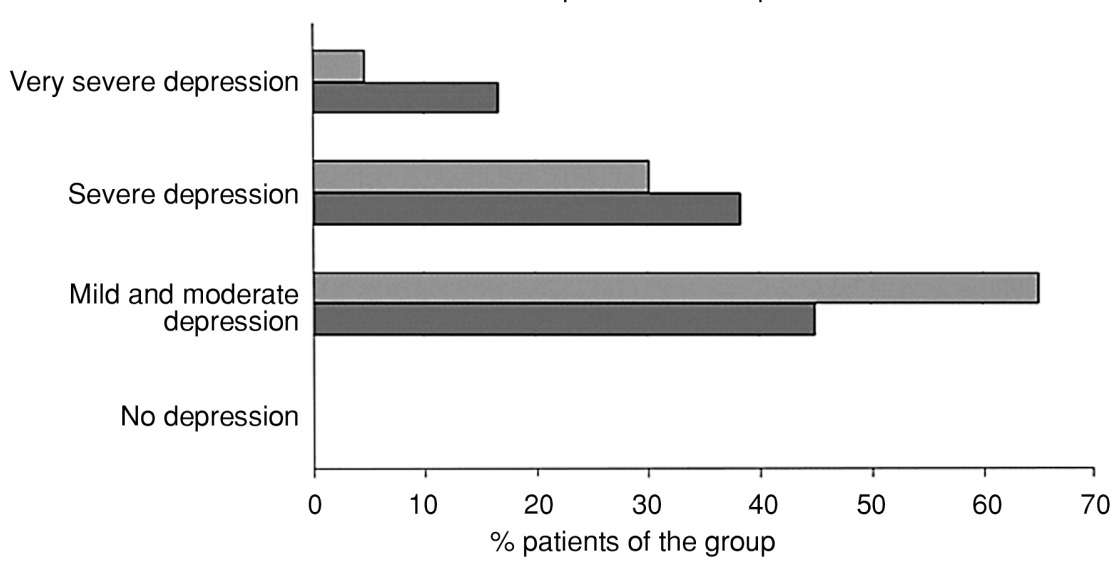

Figure 2. Percentage distribution of severity of depressive symptoms in studied groups

Table 2. Assessment of severity of depressive disorders in study groups, tested using the Beck Depression Scale.

\begin{tabular}{|c|c|c|c|c|}
\hline $\begin{array}{c}\text { Exacerbation of } \\
\text { depressive } \\
\text { disorders }\end{array}$ & No depression & $\begin{array}{c}\text { Mild and } \\
\text { moderate } \\
\text { depression }\end{array}$ & Severe depression & $\begin{array}{c}\text { Very } \\
\text { severe } \\
\text { depression }\end{array}$ \\
\hline Beck depression scale & $0-11$ & $12-26$ & $27-49$ & $50-63$ \\
\hline Group 1 N =63 & 0 & 41 & 23 & 3 \\
\hline Group 2 N =60 & 0 & 27 & 23 & 10 \\
\hline
\end{tabular}


Table 3. Drugs used to treat depressive disorders in COPD patients - comparison of treatment costs ( based on medication costs in 2016).

\begin{tabular}{|c|c|c|c|c|c|c|c|}
\hline \multirow[t]{2}{*}{$\begin{array}{c}\text { Therapeutic } \\
\text { substance/dose }\end{array}$} & \multirow{2}{*}{$\begin{array}{l}\text { Cost of monthly } \\
\text { therapy (without } \\
\text { reimbursement) } \\
\text { [euro] }\end{array}$} & \multicolumn{2}{|c|}{$\begin{array}{l}\text { Number of patients } \\
\text { taking a medication }\end{array}$} & \multicolumn{2}{|c|}{$\begin{array}{l}\text { Cost of monthly } \\
\text { therapy in the group } \\
\text { [euro] }\end{array}$} & \multicolumn{2}{|c|}{$\begin{array}{c}\text { Cost of annual } \\
\text { therapy } \\
\text { [euro] }\end{array}$} \\
\hline & & Group 1 & Group 2 & Group 1 & Group 2 & Group 1 & Group 2 \\
\hline Agomelatine $25 \mathrm{mg}$ & 35.95 & 1 & 0 & 35.95 & 0.00 & 431.40 & 0.00 \\
\hline Citalopram $20 \mathrm{mg}$ & 5.71 & 7 & 4 & 39.97 & 22.84 & 479.64 & 274.08 \\
\hline Doxepin $10 \mathrm{mg}$ & 8.57 & 4 & 2 & 34.28 & 17.14 & 411.36 & 205.68 \\
\hline Escitalopram $10 \mathrm{mg}$ & 7.14 & 10 & 12 & 71.40 & 85.68 & 856.80 & 1028.16 \\
\hline Fluoxetine $20 \mathrm{mg}$ & 5.00 & 4 & 3 & 20.00 & 15.00 & 240.00 & 180.00 \\
\hline Clomipramine $75 \mathrm{mg}$ & 5.47 & 2 & 2 & 10.94 & 10.94 & 131.28 & 131.28 \\
\hline Mianserin $30 \mathrm{mg}$ & 5.23 & 7 & 10 & 36.61 & 52.30 & 439.32 & 627.60 \\
\hline Mirtazapine $30 \mathrm{mg}$ & 10.47 & 6 & 3 & 62.82 & 31.41 & 753.84 & 376.92 \\
\hline Moclobemide $150 \mathrm{mg}$ & 4.76 & 1 & 0 & 4.76 & 0.00 & 57.12 & 0.00 \\
\hline Paroxetine $20 \mathrm{mg}$ & 4.76 & 3 & 2 & 14.28 & 9.52 & 171.36 & 114.24 \\
\hline Sertraline $50 \mathrm{mg}$ & 3.80 & 5 & 8 & 19.00 & 30.40 & 228.00 & 364.80 \\
\hline Trazodone $150 \mathrm{mg}$ & 8.10 & 4 & 2 & 32.40 & 16.20 & 388.80 & 194.40 \\
\hline \multirow[t]{2}{*}{ Venlafaxine $75 \mathrm{mg}$} & 5.95 & 8 & 10 & 47.60 & 59.50 & 571.20 & 714.00 \\
\hline & & 62 & 58 & 430.01 & 350.93 & 5160.12 & 4211.16 \\
\hline
\end{tabular}

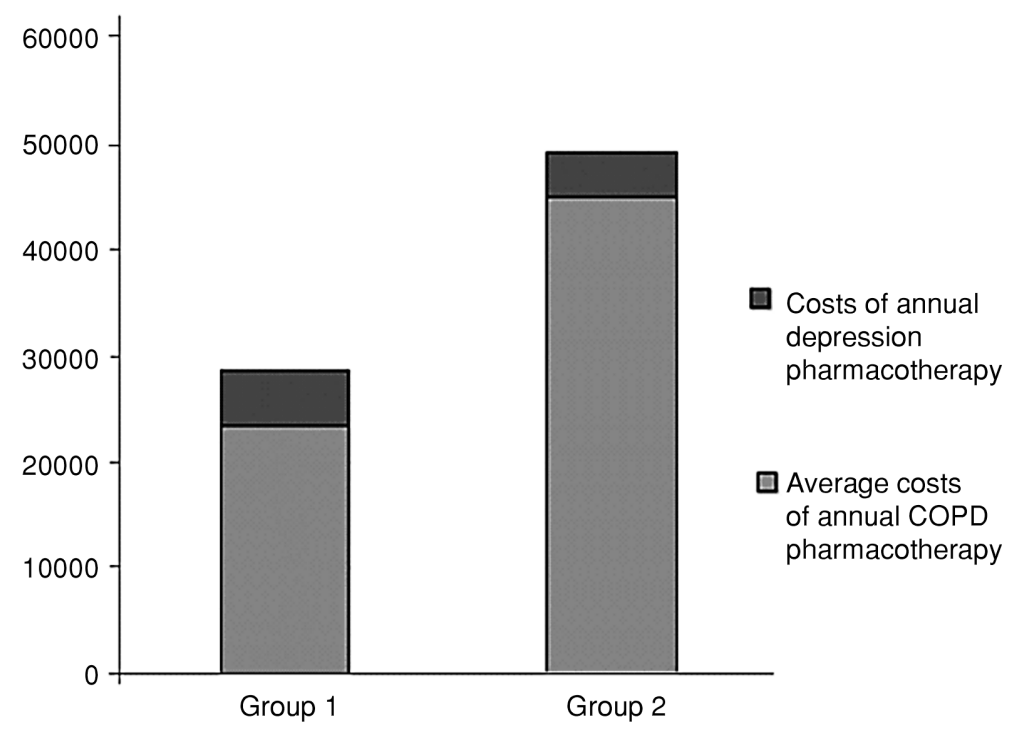

Figure 3. Comparison of general costs of COPD in combination with the cost of antidepressant treatment in the study groups

study. The results from the questionnaire analysis are presented in Table 2. In both groups, there was no one with no symptoms of depression. The percentage distribution of severity of depressive symptoms in each group is shown in Figure 2.

Because of the occurrence of depressive symptoms in patients in each study group, it was decided to introduce additional pharmacological treatment for depression. A summary of the drugs used is shown in Table 3.

Figures 3 and 4 show a comparison of the overall costs of pharmacotherapy for COPD in combination with the cost of treatment for depression and the average costs for one patient. 


\section{DISCUSSION}

Depression is defined as a mood disorder of varying degrees of severity leading to a decrease in physical and mental activity. Chronic obstructive pulmonary disease as a stressor can lead to depression, which is most often associated with dyspnea as a primary symptom in COPD (24). Anxiety cooccurring in this disease unit exacerbates dyspnea, causing the disorder in the patient to take remedial action $(25,26)$.

There are four types of dependence between depression and somatic diseases. First of all, they include the appearance of depression as a neurological complication in the CNS. Second, the occurrence of depression associated with the stress associated with the occurrence of chronic and life-threatening diseases. Further aspects are the use of certain drugs that can cause serious mood disturbances and that somatic disease can occur in a person suffering from a depressive disorder.

Causes and pathogenesis of COPD are complex, and sources should be sought in the pathogenic effect of the disease itself on the central nervous system (27). For COPD patients, somatic symptoms include increased dyspnea associated with reduced physical activity, excessive chronic activation of post-inflammatory cytokines, hypoxia associated with respiratory failure. The relationship between genetic predisposition and the undesirable effects of systemic steroids, as well as psychological and social causes, are also important (28).
As reported by the study, depression occurs in about $60 \%$ of COPD patients $(4,29)$. The occurrence of depressive symptoms is more than 3.5 times higher in smokers compared to non-smokers (28).

The study was intended to draw attention to a very often overlooked aspect of the mental condition of patients. The occurrence of depressive symptoms in patients with COPD may be a factor worsening the quality of life and increasing the frequency of exacerbations and hospitalizations. Psychiatric disorders have a very negative impact on the clinical picture, especially in patients with severe and very severe COPD (15). However, depression should also be considered as a consequence of the disease, deteriorating quality of life and more frequent exacerbations. Psychiatric disorders that occur during longterm illness have a greater impact on the quality of life of patients with primary symptoms of COPD specific to the disease phase. These disorders tend to progressively increase with the "vicious circle" model, interacting with each other, and with signs of COPD. In this aspect, social education, preparing patients for the possibility of deteriorating mental condition or early intervention of a psychotherapist or psychiatrist may delay or minimize the occurrence of depressive symptoms accompanying COPD.

The aim of the study was to assess the prevalence and severity of depressive symptoms in patients with medium-severe and severe forms of COPD and to assess the cost of coexistence of depression in these patient groups.

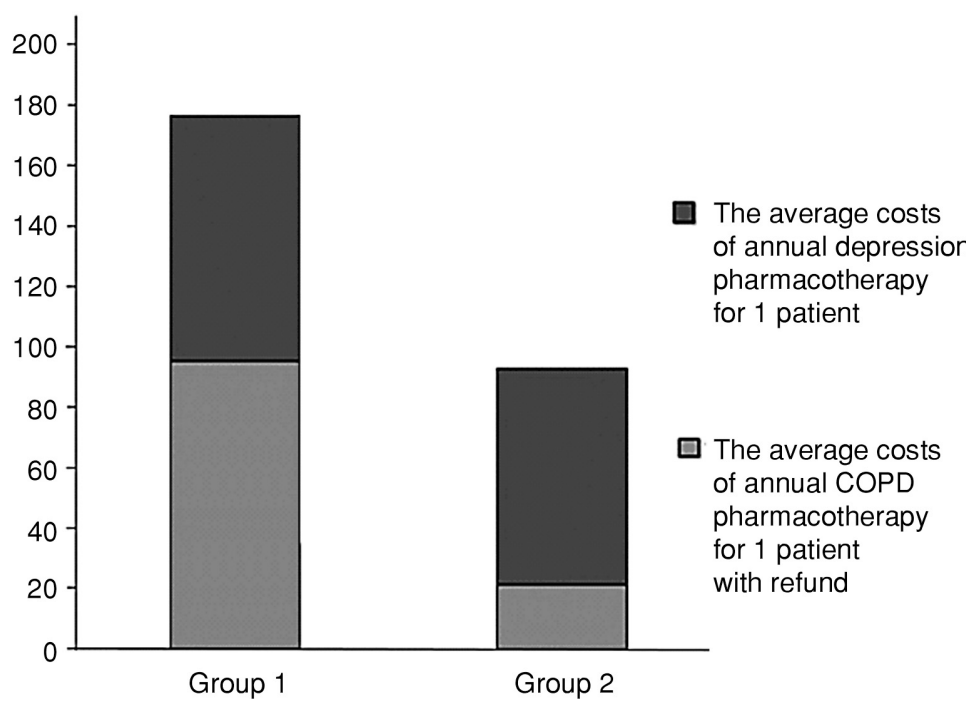

Figure 4. Comparison of general costs of COPD in combination with the cost of antidepressant treatment per 1 patient in study groups 
The study was attended by patients with medium-severe and severe COPD, with co-morbid depressive disorders. Group 1 included 63 patients with mild dyspnea $(\mathrm{mMRC}=1)$ or mild COPD symptoms $(\mathrm{CAT}<10)$. Patients in this study group defined depression symptoms as mild depression- 41 (65\%), moderately severe depression- 19 (30\%) and very severe depression- 3 (5\%). Group 2 included 60 patients with severe dyspnea $(\mathrm{mMRC}=2)$ or severe and very severe COPD symptoms $(\mathrm{CAT}=10)$. The results of research in this group suggest that mild depressive symptoms occurred in 27 patients (45\%), moderately severe depression in 23 patients $(38 \%)$ and very severe depression in $10(17 \%)$. Our study is also confirmed by the results of studies from centers in different countries where the assessment of the severity of depressive disorders was made using the BDI 21-factorial depression questionnaire (31-34).

The COPD direct costs in 2014 amounted to 441.8 million PLN. The largest share of this figure was 297.1 million PLN, comprised of the cost of remedial drugs consisting of the reimbursement of medicines by the public payer (250.8 million PLN) and patient surcharges (46.3 million PLN). The median cost of chronic obstructive pulmonary disease in 2014 was between 5620.2 and 6409.9 million PLN. The largest share of indirect costs was the cost of presenteeism (between 4845.7 and 5635.4 million PLN), incapacity costs (495.6 million PLN) and premature death (180.9 million PLN). The cost of absenteeism was 97.4 million PLN, and additionally the absenteeism of informal cares was about 0.6 million PLN (35).

It is worth noting that coexisting illnesses, such as depression, and the accompanying complications, as well as the inclusion of costs generated by undiagnosed patients, represent a significant cost burden. Such a thesis is confirmed by the results of our research. However, there are still no reliable studies evaluating the differences in basic parameters defining the quality of life of the patients after treatments applied. We can only assume that the antidepressant treatment will raise the indicators describing: family and social relationships, ability to work, complacency. This should consequently be reflected in the indirect costs associated with COPD treatment. However, until such studies have been carried out so far collected results allow to draw the following conclusions:

- treatment of COPD, especially in advanced stages of the disease, requires the use of pharmacological therapy which should be complemented by non-pharmacological treatment,
- in order to reduce direct costs, the need for treatment of COPD patients with psychopharmacotherapy and psychotherapy should be considered,

- in patients with dyspnea, psychological counseling seems to be suggested to prevent or to teach behavior with anxiety attacks and depressive disorders,

Routine search and use of optimal therapy for depressive disorders should be considered for patients treated with COPD because depression increases the risk of hospitalization and premature death from COPD.

\section{Limitation of the study}

Our research has several limitations worth mentioning. First, information about smoking, social relationships, patient's education was unavailable from the data, which may be related to depression. Secondly, incorrect diagnosis may appear. The Beck Depression Scale which we used as a measure for depression is designed to detect the presence of clinically significant depressive symptoms but is not tantamount to a diagnosis of clinical depression. Among participants with COPD, the estimation of effects was limited by the small and unbalanced number of depressed and non-depressed subjects. Other COPD outcomes such as mortality and health resource use are also relevant but were not studied. Finally, due to the limited number of published studies, further longitudinal studies are required.

\section{REFERENCES}

1. http://www.goldcopd.com (accessed on 02. 03. 2018).

2. Mannino D.M.: Respir. Care 48, 1185 (2003).

3. http://www.who.int.respiratory/copd/burden/ en/ (accessed on 03. 03. 2018).

4. Yohannes A.A.M., Baldwin R.C., Connolly M.J.: Age Ageing 35, 457 (2006).

5. Godoy D.V., Godoy R.F.: Arch. Phys. Med. Rehab. 84, 1154 (2003).

6. Gysels M.H., Higginson I.J.: Chronic Respir. Dis. 6, 133 (2009).

7. Howard C., Hallas C.N., Wray J., Carby M.: Behav. Res. Ther. 47, 71 (2009).

8. Patten S.B., Williams J.V.A., Lavorato D.H., Modgill G., Jette N. et al.: Gen. Hosp. Psychiatry 30, 407 (2008).

9. Vögele C., von Leupoldt A.: Respir. Med. 102, 764 (2008).

10. Mikkelsen R.L., Middelboe T., Pisinger C., Stage K.B.: Nord. J. Psychiatr. 58, 65 (2004). 
11. van Manen J.G., Bindels P.J.E., Dekker F.W., Ijzermans C.J., van der Zee J.S. et al.: Thorax 57, 412 (2002).

12. Hynninen K.M.J., Breitve M.H., Wiborg A.B., Pallesen S., Nordhus I.H.: J. Psychosom. Res. 59, 429 (2005).

13. Hanania N.A., Mullerova H., Locantore N.W. et al.: Am. J. Respir. Crit. Care Med. 183, 604 (2011).

14. Kunik M.E., Roundy K., Veazey C.,Souchek J., Richardson P. et al.: Chest 127, 1205 (2005).

15. Ng T.P., Niti M., Tan W.C., Cao Z., Ong K.C. et al.: Arch. Intern. Med. 167, 60 (2007).

16. Maurer J., Rebbapragada V., Borson S., Goldstein R., Kunik M.E. et al.: Chest 134, 43 (2008).

17. www.nice.org.uk/nicemedia/pdf/CG91FullGuideline.pdf (accessed on 10. 03. 2018).

18. Global Initiative for Chronic Obstructive Lung Disease (GOLD report). Global Strategy for COPD Diagnosis, Management, and Prevention. Update 2017.

19. https://goldcopd.org/wp-content/uploads/ 2016/12/wms-GOLD-2017-Pocket-Guide.pdf (accessed on 10. 03. 2018).

20. Teramoto S., Inui T., Hizawa N.: Int. J. Chron. Obstruct. Pulmon. Dis. 10, 2203 (2015).

21. Beck A.T., Ward C.H., Mendelson M., Mock J., Erbaugh J.: Arch. Gen. Psychiatry 4, 53 (1961).

22. Jaracz K., Wołowicka L., Trojanowska I., Bartkowska - Śniadkowska A., Torliński T. et al.: Qual. Life Res. 8, 352 (1999) (in Polish).

23. Wołowicka L., Bartkowska-Śniatkowska A., Trojanowska I., Torliński T., PodlaszewskaKirkor J. et al.: Quality of life in medical sciences. Wołkowicka L. (ed.). Medical Academy K. Marcinkowski, Poznań 2001 (in Polish).
24. Carrasco Garrido P., de Miguel Díez J., Rejas Gutiérrez J., Centeno A.M., Gobartt Vázquez E. et al.: Life Outcomes 4, 31 (2006).

25. Janssen D.J., Spruit M.A., Leue C., Gijsen C., Hameleers H. et al.: Chron. Respir. Dis. 7, 147 (2010).

26. Thomas S., Bausewein C., Higginson I., Booth S.: Eur. J. Oncol. Nurs. 15, 459 (2011).

27. von Leupoldt A., Mertz C., Kegat S., Burmester S., Dahme B. et al.: Pathophysiology 43, 382 (2006).

28. Iosifescu D.V.: Psychiatr. Clin North. Am. 30, 77 (2007).

29. Hill K., Geist R., Goldstein R.S., Lacasse Y.: Eur. Respir. J. 31, 667 (2008).

30. Gudmundsson G., Gislason T., Janson C., Lindberg E., Ulrik C.S. et al.: Respir. Med. 100, 87 (2006).

31. Wagena E.J., Arrindell W.A., Wouters E.F.M., Schayck van C.P.: Eur. Respir. J. 26, 242 (2005).

32. McCathie H., Spence S., Tate R.: Eur. Respir. J. 19, 47 (2002).

33. Di Marco F., Verga M., Reggente M., Casanova F.M., Santus P. et al.: Respir. Med. 100, 1767 (2006).

34. Eisner M.D., Blanc P.D., Yelin E.H., Katz P.P., Sanchez G. et al.: Thorax 65, 229 (2010).

35. De Voogd J.N., Altenburg W.A., Wempe J.B., van der Vaart H.: European Health Psychologist 17, 615 (2015).

36. Costs of Chronic Obstructive Pulmonary Disease in Poland - EY study

37. http://www.ey.com/Publication/vwLUAssets/ KosztyPOChP/\$FILE/Raport-Koszty-POChPglowne-wnioski.pdf (accessed on 20. 03. 2018) (in Polish).

Received: 26.05. 2018 